\title{
Effectiveness of rifaximin and fluoroquinolones in preventing travelers' diarrhea (TD): a systematic review and meta-analysis
}

\author{
Sanjin Alajbegovic ${ }^{1}$, John W Sanders ${ }^{2}$, Deborah E Atherly ${ }^{3}$ and Mark S Riddle $2^{2^{*}}$
}

\begin{abstract}
Background: Recent developments related to a safe and effective nonabsorbable antibiotic, rifaximin, and identification of postinfectious irritable bowel syndrome as a frequent sequela call for a need to reconsider the value of primary prevention of traveler's diarrhea (TD) with antibiotics.

Methods: Randomized, placebo-controlled, double-blind studies evaluating the effectiveness and safety of rifaximin or a fluoroquinolone chemoprophylaxis against TD were pooled using a random effects model and assessed for heterogeneity.

Results: The nine studies (four rifaximin and five fluoroquinolone) included resulted in pooled relative risk estimates of $0.33\left(95 \% \mathrm{Cl}=0.24-0.45, P^{2}=3.1 \%\right)$ and $0.12(95 \% \mathrm{Cl}=0.07-0.20, P=0.0 \%)$, respectively. Similar rates of treatment emergent adverse events were found between antibiotic and placebo groups.

Conclusions: This meta-analysis supports the effectiveness of antibiotics in preventing TD. However, further studies that include prevention of secondary chronic health outcomes among travelers to different geographic regions, and a formal risk-benefit analysis for antibiotic chemoprophylaxis, are needed.
\end{abstract}

Keywords: Travelers' diarrhea, Chemoprophylaxis, Systematic review, Meta-analysis, Rifaximin, Fluoroquinolone

\section{Background}

Travelers' diarrhea (TD) is one of the most frequent health problems encountered by individuals traveling from developed to less-developed countries [1]. Although the illness rarely results in a serious health outcome, these infections of predominantly bacterial origin can cause significant morbidity and costs resulting from incapacitation while traveling and can disrupt valuable business and leisure excursions. Furthermore, evidence is accumulating that these infections can lead to long-term health consequences, including functional bowel disorders such as irritable bowel syndrome [2]. Such recognition of the acute and chronic impacts of these infections has raised the importance of primary disease prevention.

Prevention of TD is challenging because of the ubiquitous exposure to individuals through contaminated food, water and generally unhygienic conditions in much of the

\footnotetext{
* Correspondence: mark.riddle@med.navy.mil

${ }^{2}$ Naval Medical Research Center, Silver Spring 20910-7500 MD, USA

Full list of author information is available at the end of the article
}

developing world. Travelers are frequently counseled on preventive risk behaviors, but, despite a traveler's best attention to such recommendations, evidence is lacking that such precautions have any protective effect [3]. Although vaccines for many of the agents commonly associated with TD are under development, this is considered a long-term solution and might likely suffer from lack of utilization as has been seen with most travel-associated vaccines [4-8].

Antimicrobial prophylaxis has been considered an option to prevent infection. In 1985, issues surrounding prophylaxis were debated during a National Institutes of Health (NIH)-sponsored consensus meeting, which concluded that routine antibiotic chemoprophylaxis should not be used because of concerns about the development of antibiotic resistance, the demonstrated efficacy of empiric therapy after the development of symptoms, and the potential for unnecessary side effects [9]. Since that meeting, studies that have examined the costs versus benefits of chemoprophylaxis for the prevention of TD have recommended against prophylaxis except in high-risk groups [10,11]. Although 
debate continues, the standard practice and recommendation have remained unchanged for 20 years [12-14].

Two recent developments are challenging the general recommendation against use of chemoprophylaxis. First, postinfectious irritable bowel syndrome (PI-IBS) has been recognized as an important post-TD sequela, occurring in approximately $7 \%$ of those who experience an enteric infection, particularly among those with bacterial infection and a more severe clinical presentation $[15,16]$. Second, rifaximin, a nonabsorbable antibiotic, has been developed and may provide a safer alternative for prophylaxis than fluoroquinolones, which are known to be quite effective but may have an unacceptable safety profile. The high volume of international travel, and, consequently, the high number of people at risk from acquiring TD, PI-IBS and other postinfectious chronic health conditions, create a potentially large burden of illness that could be prevented with the use of safe and effective chemoprophylaxis. A number of traditional and systematic qualitative reviews on the use of chemoprophylaxis, and in particular rifaximin, have been reported in the past few years and have generally favored the consideration of rifaximin for prevention of TD among high-risk groups or the risk-averse traveler [17-21]. However, those studies rarely assess the quality of the studies being reviewed and often do not result in a summary effect estimate of an intervention, which can be of further use for analytic decision-making and cost-benefit analysis. In addition, due to the nature of those reviews, they can be subject to bias and may not adequately consider disparate findings. Therefore, the objective of this study was to conduct a systematic review of the literature on the effectiveness and safety of rifaximin and fluoroquinolone antibiotics in the prevention of TD.

\section{Methods}

This systematic review and meta-analysis was conducted according to the guidelines set forth in the Cochrane Handbook for Systematic Reviews of Interventions [22].

\section{Literature search and study selection}

A comprehensive literature search was performed to identify all randomized, double-blind, placebo-controlled trials that evaluated effectiveness of rifaximin or a fluoroquinolone in preventing TD. Studies that examined other antibiotics were excluded because currently the only clinically relevant antibiotics for preventing TD are rifaximin and fluoroquinolones. The population of interest comprised adult civilian or military travelers. Studies were identified using the electronic databases PubMed (through April 2012) and Embase (through April 2012) and consultation with experts in the field. The following search strategy was used on PubMed: "travel" diarrh" and "travel" (MeSH). The search was limited to studies on human subjects and published in English. Citations from retrieved articles were examined for primary outcome data completeness, and studies that reported rates of TD in treatment and control groups were included in the meta-analysis. In addition, consultation with experts in the field was used to identify any missing articles. Eligibility of all articles for systematic review and meta-analysis was confirmed by two investigators (SA and MR). The details of the literature search and study selection are presented in Figure 1.

\section{Data abstraction and risk of bias assessment}

Data were collected from each study and recorded on a data abstraction form, which was designed a priori and pilot-tested on three studies. Primary data abstraction was performed by an investigator (SA) and validated independently by another investigator (JS) before the data were used for statistical analysis. The primary end point of interest was the overall risk reduction in incidence of TD in treatment versus control group with the intention-to-treat (ITT) sample sets of each study. Secondary end points of interest included per-protocol (PP) risk reduction, efficacy against moderate to severe TD and safety of prophylactic antibiotics as measured by rates of drug-attributed adverse events (AEs) in treatment and control groups and/or other noted clinically significant AEs. Other information that was abstracted from each study included first author, publication name and year published, article title, study design, country of traveler/travel, year of study, proportion male, mean/median age, antibiotic dose and frequency, duration of therapy, travel purpose, and follow-up posttherapy, time of therapy initiation relative to arrival, list of exclusion criteria, definition of TD used and any other definitions of TD used (mild, moderate or severe), initial number of subjects randomized to each study arm, number of subjects that completed follow-up schedule in each study arm, overall incidence of TD at week 1 and week 2 after initiating intervention (PP and ITT data), and the incidence of moderate/ severe TD (PP and ITT data).

The risk of bias assessment was performed independently by two investigators (SA and JS) using guidelines set forth in the Cochrane Handbook [22]. Seven domains were evaluated for bias (random sequence generation, allocation concealment, blinding of participants and personnel, blinding of outcome assessment, incomplete outcome data, selective reporting and other bias). Criteria for the "other bias" domain were discussed and specified a priori and included an assessment of the bias associated with exposure risk (single vs. multiple travel locations, seasonal variation of travel and the risk level of the participant) and assessment of adherence to randomized regimen. Each domain was assigned one of the following qualitative scores: "low risk," "high risk" or "unclear risk." In general, if there was evidence of bias, the study was deemed to be "high risk" for bias for that specific domain. An "other bias" domain of risk assessment took into consideration adherence 


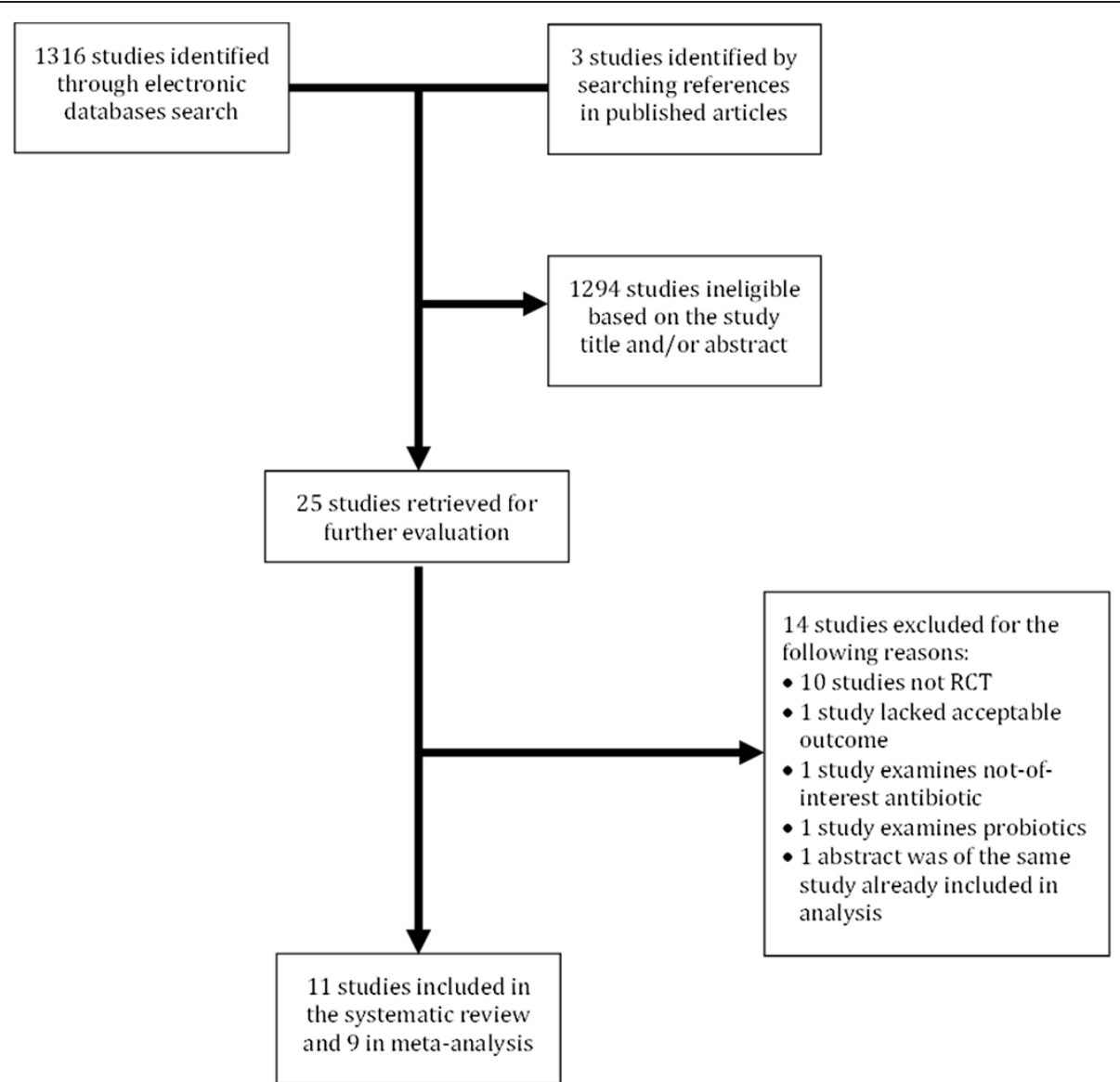

Figure 1 Flow diagram of literature review, eligibility determination and inclusion in the systematic review and meta-analysis. $R C T$, randomized controlled trial.

assessment/reporting and bias associated with exposure risk. Discordant assessments for each domain of each article were discussed and adjudicated by reaching consensus among three investigators (SA, MR and JS).

\section{Data analysis}

The proportion of subjects experiencing TD in treatment and control groups (dichotomous outcome) was used to determine the relative risk of developing TD when a chemoprophylactic antibiotic was administered versus placebo. Relative risks were then pooled independently for fluoroquinolones and rifaximin to determine the overall effect of chemoprophylactic antibiotic treatment with a $95 \%$ confidence interval (CI). Given the heterogeneity of study designs, population, and dosing regimens, a conservative approach was employed for all analyses based on a random effects model of the DerSimonian and Laird (D\&L) method to reflect both within- and between-study variability. Relative risk of 1 indicated that chemoprophylaxis did not reduce the incidence of TD any more than placebo. Risk differences were similarly pooled for purposes of estimating numbers needed to treat to prevent an episode of TD while traveling.
Sensitivity analyses were performed graphically by observation of differences in pooled relative risks based on withindrug-class study characteristics and for PP versus ITT data. Incidence of moderate/severe TD was only pooled for fluoroquinolone studies since only one rifaximin study reported rates of severe TD in treatment and placebo groups. Heterogeneity was explored visually and statistically using the heterogeneity $x^{2}$ and the inconsistency index statistic $\left(I^{2}\right)$. Publication bias was assessed using the method described by Harbord et al. [23]. All analyses were done using Stata version 12.1 software (StataCorp, College Station, TX, USA).

\section{Results}

\section{Study selection and study characteristics}

Electronic database, manual reference search and consultation with experts in the field yielded 11 studies that were included in the systematic literature review and 9 that were included in a meta-analysis [24-34] (Table 1). The study by Parry et al. was not included in the meta-analysis because it did not define TD [29], and the study by Taylor et al. was a human experimental challenge study and thus was not conducted in a field efficacy setting [32]. Nine studies 
Table 1 Characteristics of studies included in systematic review and meta-analysis for protective efficacy against travelers' diarrhea

\begin{tabular}{|c|c|c|c|c|c|c|c|c|c|}
\hline Author & $\begin{array}{l}\text { Country of } \\
\text { traveler }\end{array}$ & $\begin{array}{l}\text { Country of } \\
\text { travel }\end{array}$ & Population & Study design & $\begin{array}{l}\text { Antibiotic } \\
\text { evaluated }\end{array}$ & Dose and frequency & $\begin{array}{l}\text { No. of patientsin } \\
\text { allregimens }\end{array}$ & $\begin{array}{l}\text { Duration of } \\
\text { therapy }\end{array}$ & $\begin{array}{l}\text { Protective } \\
\text { Efficacy }\end{array}$ \\
\hline \multicolumn{10}{|c|}{ Studies reviewed and included in meta-analysis } \\
\hline Johnson et al. (1986) [24] & USA & Mexico & Language school & $\mathrm{R}, \mathrm{DB}, \mathrm{PC}$ & Norfloxacin & 400 mg daily & 115 & 14 days & $88 \% *$ \\
\hline Wistrom et al. (1987) [31] & Sweden & $\begin{array}{l}\text { Africa, Asia, South } \\
\text { America }\end{array}$ & NS & $R, D B, P C$ & Norfloxacin & $200 \mathrm{mg}$ bid & 115 & 5 to 21 days & $84 \% *$ \\
\hline Scott et al. (1990) [34] & USA/Italy & Egypt & Military & $R, D B, P C$ & Norfloxacin & $400 \mathrm{mg}$ daily & 222 & 7 days & $93 \% *$ \\
\hline Rademaker et al. (1989) [30] & $\begin{array}{l}\text { The } \\
\text { Netherlands }\end{array}$ & Tunisia & Leisure & $R, D B, P C$ & Ciprofloxacin & $500 \mathrm{mg}$ daily & 53 & 8 days & $94 \% *$ \\
\hline Heck et al. (1994) [33] & USA & $\begin{array}{l}\text { Central and South } \\
\text { America }\end{array}$ & Volunteering & $R, D B, P C$ & Ciprofloxacin & $500 \mathrm{mg}$ daily & 278 & 5 to 14 days & $85 \% *$ \\
\hline DuPont et al. (2005) [26] & USA & Mexico & Language school & $\mathrm{R}, \mathrm{DB}, \mathrm{PC}$ & Rifaximin & 200 mg daily, bid, tid & 210 & 14 days & $73 \%^{*, a}$ \\
\hline Armstrong et al. (2010) [25] & USA & Turkey & Military & $R, D B, P C$ & Rifaximin & 1,100 mg daily & 95 & 14 days & $67 \%$ \\
\hline $\begin{array}{l}\text { Martinez-Sandoval et al. } \\
\text { (2010) [28] }\end{array}$ & USA & Mexico & Language school & $R, D B, P C$ & Rifaximin & 600 mg daily & 201 & 14 days & $68 \% *$ \\
\hline Flores et al. (2011) [27] & USA & Mexico & Language school & $R, D B, P C$ & Rifaximin & $550 \mathrm{mg}$ daily & 98 & 14 days & $28 \%$ \\
\hline \multicolumn{10}{|c|}{ Other studies of relevance reviewed but not included in meta-analysis } \\
\hline Parry et al. (1994) [29] & UK & Nepal & Himalayan expedition & $\mathrm{R}, \mathrm{DB}, \mathrm{PC}$ & Ciprofloxacin & 250 mg daily & 21 & 28 days & NA \\
\hline Taylor et al. (2006) [32] & NA & NA & Volunteers & $R, D B, P C$ & Rifaximin & $200 \mathrm{mg}$ tid & 25 & 3 days & NA \\
\hline
\end{tabular}

${ }^{a}$ Rifaximin groups combined. Note: Studies are listed in chronological order by an antibiotic studied. bid = twice daily; tid = three times daily; R, DB, PC = randomized, double-blind, placebo-controlled; NA = not available; NS $=$ not specified. *Statistically significant. 
included in the meta-analysis had a total of 1,310 subjects, with 604 subjects in rifaximin studies and 706 subjects in fluoroquinolone studies. Four studies examined the effectiveness of rifaximin in preventing TD, and one of those studies (DuPont et al.) had three treatment arms (rifaximin dosed once, twice or three times daily) and one control arm (placebo dosed three times daily) [25-28]. The remaining five studies utilized a fluoroquinolone (three norfloxacin and two ciprofloxacin) and included single dose $(n=4)$ and one twice daily regimen. Overall, among nine studies, a median attack rate of $34.5 \%$ (interquartile range $[\mathrm{IQR}]=20.3 \%$ to $53.7 \%$ ) was found in the placebo groups, and attack rates were similar between the rifaximin studies (median $33.1 \%, \mathrm{IQR}=17.9 \%$ to $50.4 \%$ ) and the fluoroquinolone studies (median $34.5 \%, \mathrm{IQR}=25.6 \%$ to $61.0 \%$ ) $(P=0.32$, Kruskal-Wallis test). There was greater diversity in traveler populations and geographic destinations for studies evaluating fluoroquinolone efficacy compared to those evaluating rifaximin. Duration of intervention was on average 14 days, and TD definitions were generally similar across all studies, except one (Heck et al. [33]), where TD was defined as $\geq 3$ loose stools/8-hour period plus $\geq 1$ associated symptom (vs. standard definition of TD, $\geq 3$ loose stools/24-hour period plus $\geq 1$ associated symptom) which may have underestimated the incidence of TD in the treatment and placebo groups.

\section{Risk of bias assessment}

All studies were deemed to have "low risk" of bias in domains of allocation concealment, blinding of participants and personnel, and blinding of outcome assessment (Figure 2). Although no study specified whether blinding of outcome assessment took place, investigators deemed that, owing to the relatively objective nature of the clinical outcome and standard use of definitions, low risk for bias existed even if the outcome assessment was not blinded. Four studies did not specify the process of randomization and were therefore assigned "unclear risk" for random sequence generation domain. DuPont et al. [26] had significantly different attrition rates between treatment and control groups, and Heck et al. [33] reported a relatively high attrition rate that was not adequately handled/reported; therefore, both studies were assigned "high risk" for the incomplete outcome data domain. Unclear risk in incomplete outcome data domain was assigned to the study by Armstrong et al. because of the low number of stool specimens collected, an end point that was prespecified in the Methods section of the study [25]. A single study had high risk for bias in selective data reporting domain due to the fact that an ITT outcome for the primary end point was not available [33].

\section{Primary outcome: prevention of TD in ITT analyses}

ITT data from studies examining fluoroquinolones and rifaximin were pooled by drug class to determine whether antibiotic chemoprophylaxis was effective in preventing TD (Figure 3). Among the rifaximin studies, two of the four studies showed a statistically significant treatment effect and one demonstrated marginal statistical significance. There was no observed significant difference of risk reduction among dosing regimens in the DuPont et al. study, and the overall pooled D\&L effect (relative risk [RR]) estimate for all studies combined was $0.33(95 \% \mathrm{CI}=0.24$ to $0.45)$, equating to a protective efficacy of $67 \%(95 \% \mathrm{CI}=55 \%$

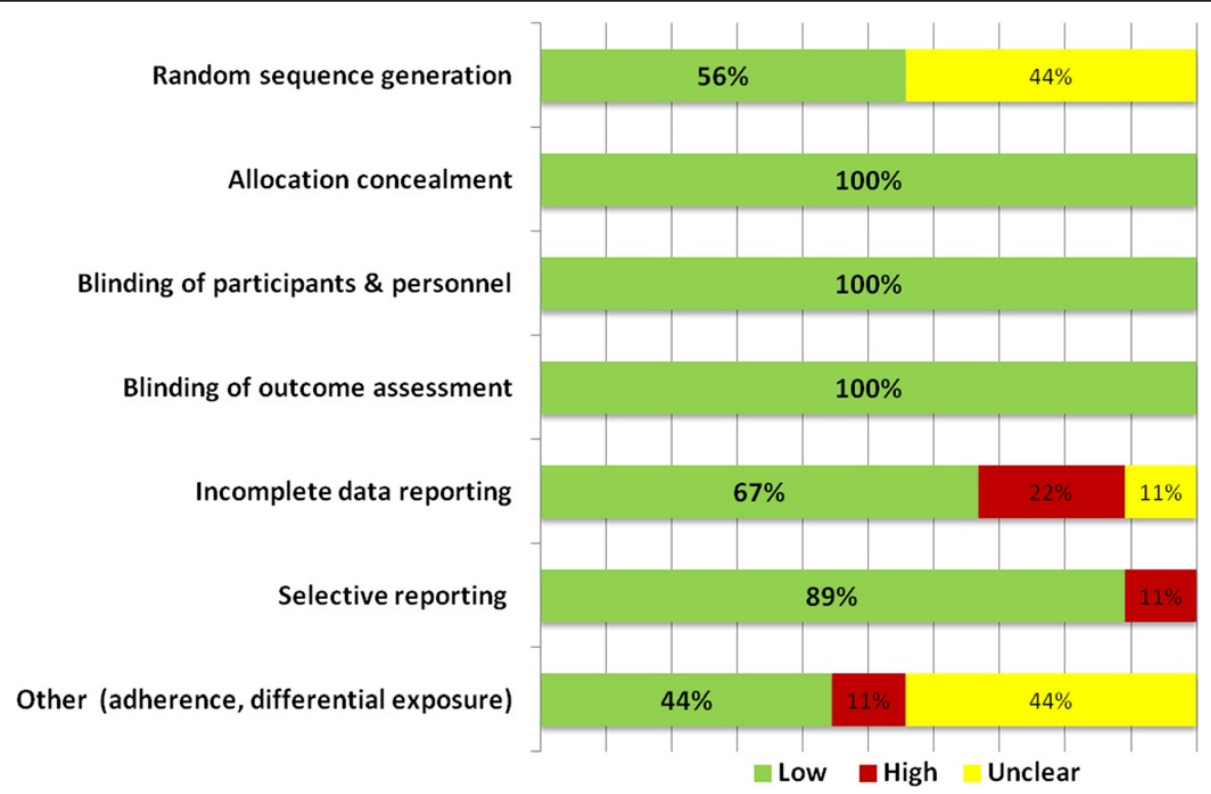

Figure 2 Frequency distribution of assessment of bias scoring among included studies in meta-analysis $(n=9)$. 


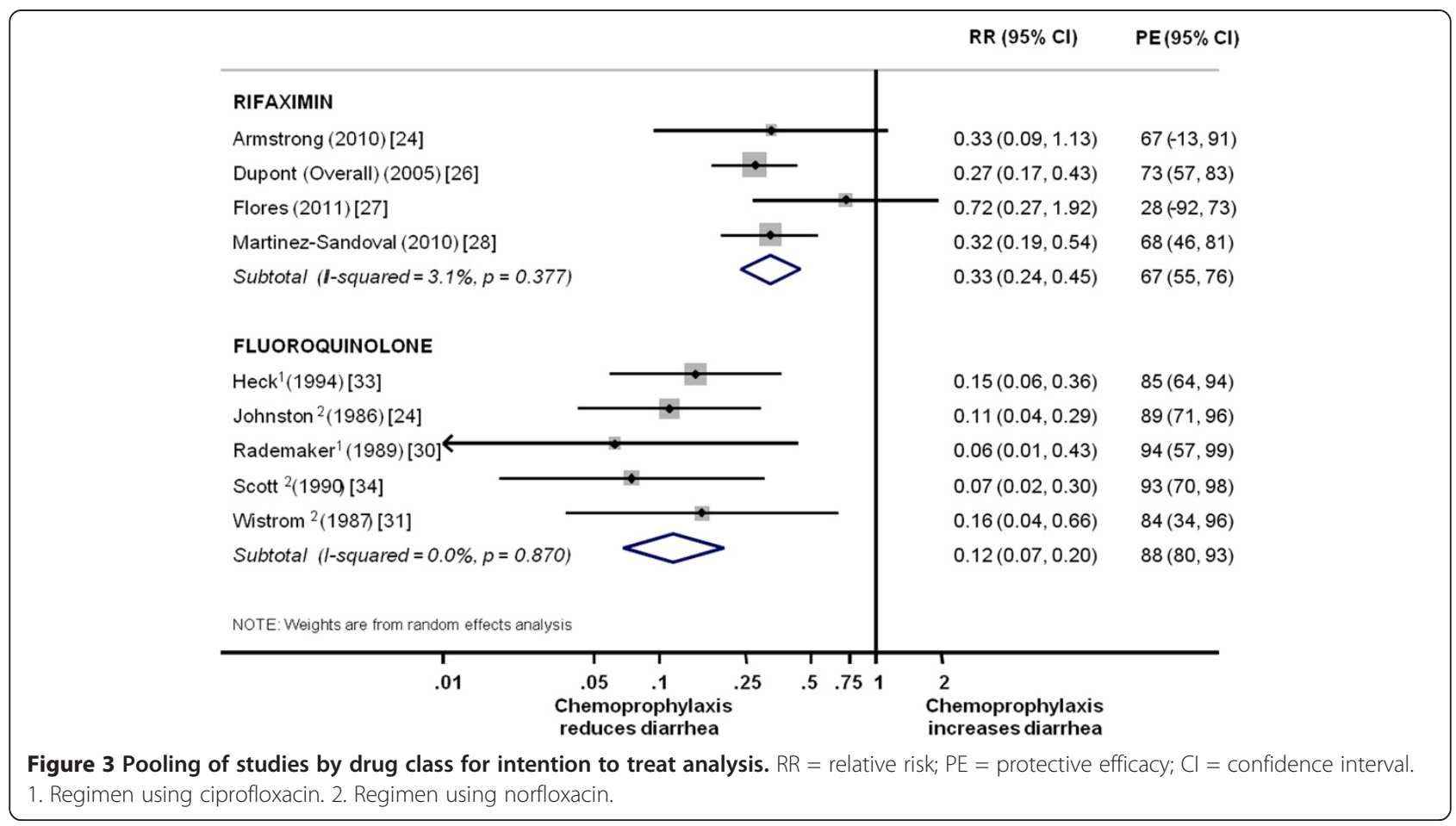

to $76 \%$ ) favoring chemoprophylaxis (heterogeneity $\chi^{2}=3.09$, $\left.P=0.377 ; I^{2}=3.1 \%\right)$. In terms of absolute risk reduction, pooled D\&L summary estimates found that rifaximin chemoprophylaxis decreased TD attack rates by a mean of $22.1 \%$ (95\% CI $=6.3 \%$ to $37.9 \%$ ) equating to a number needed to treat $(\mathrm{NNT})$ of 4.5 people $(95 \% \mathrm{CI}=2.6$ to 15.9 ) who needed chemoprophylaxis to prevent one episode of TD. All five of the studies evaluating fluoroquinolone-based regimens showed a statistically significant effect with a pooled D\&L effect RR estimate of $0.12(95 \% \mathrm{CI}=0.07$ to $0.20)$, equating to a protective efficacy of $88 \%$ ( $95 \% \mathrm{CI}=80 \%$ to $93 \%$ ) favoring chemoprophylaxis (heterogeneity $\chi^{2}=1.25$, $\left.P=0.87 ; I^{2}=0.0 \%\right)$. Risk reduction for fluoroquinolone-class antibiotics was estimated with a D\&L pooled mean of $35.5 \%$ ( $95 \% \mathrm{CI}=21.2 \%$ to $49.8 \%$ ), equating to a NNT of $2.8(95 \%$ $\mathrm{CI}=2.0$ to 4.7$)$. For both drug classes, there was no indication of publication bias (rifaximin, $P=0.63$; fluoroquinolones, $P=0.56)$.

Further exploration of the studies by drug class was conducted and based on a subanalysis of the effect of pooling data from stratification of the Dupont et al. study including once-daily treatment arm, treating three different treatment arms as if they were independent studies, and combining results from three different treatment arms [26]. When slightly different pooled relative risks were examined, all analytical strategies still favored chemoprophylaxis with rifaximin over placebo (daily: $\mathrm{RR}=0.34,95 \% \mathrm{CI}=0.22$ to 0.51 ; independent: $\mathrm{RR}=0.32 ; 95 \% \mathrm{CI}=0.24$ to 0.43 ; combined: $\mathrm{RR}=0.33 ; 95 \% \mathrm{CI}=0.24$ to 0.45$)$. On the basis of the similarity of these effect estimates, a decision was made to use a combined estimate from all three dosing regimens for purposes of further analysis. Further exploration of heterogeneity within each drug class was challenging, given the small number of studies. The study by Flores et al. stands out compared to the other studies included in this systematic review and differed only in nonsummer enrollment period compared to the other studies conducted in similar populations in Mexico [27].

\section{Secondary outcomes: prevention of TD in PP analyses and moderate to severe disease}

Analysis of efficacy in the PP sample set was available for all four studies in the rifaximin drug class. (Note: PP data were provided by one of the coauthors, MR, for the Armstrong et al. study [25].) The D\&L summary pooled RR effect estimate was 0.27 (95\% CI $=0.17$ to 0.43 ) and tended toward moderate heterogeneity (heterogeneity $\chi^{2}=5.43, \mathrm{p}=0.14$; $\left.\mathrm{I}^{2}=44.7 \%\right)$. Only three studies within the fluoroquinolone drug class included outcome data from subanalysis of moderate to severe TD and compared to placebo, though definitions varied across these studies. Rademaker et al. defined severe diarrheal illness as "symptoms of vomiting and/or fever $>38^{\circ} \mathrm{C}$," whereas Heck et al. and Johnson et al. defined confirmation of moderate to severe TD by the presence of Shigella spp. [24,30,33] and outcome events of moderate to severe TD was low (five, two and three cases, respectively, for both treatment and placebo groups combined). Considering these limitations, however, a pooled 
D\&L relative risk against moderate to severe TD of 0.51 (95\% CI $=0.095$ to 2.71 ) with low heterogeneity (heterogeneity $\left.X^{2}=2.08, P=0.354, I^{2}=3.8 \%\right)$ was found and represented poorer efficacy compared to prevention against all levels of TD severity.

\section{Secondary outcome: safety and adverse events}

The incidence of treatment emergent AEs was not reported consistently across studies. AEs of note occurred in subjects taking fluoroquinolones. Treatment emergent AEs reported in studies examining fluoroquinolones included a rash that resolved after norfloxacin was discontinued [24], enlargement of parotid glands [31], and sunburn in a subject taking ciprofloxacin [30]. Otherwise, all reported rates of AEs were similar between treatment and control groups, and no clinically significant events developed during chemoprophylaxis with rifaximin or a fluoroquinolone.

\section{Review of studies not included in meta-analysis}

Two clinical trials not included in the meta-analysis should be considered in review of the potential effectiveness of antibiotic chemoprophylaxis for the complementary evidence they may bring forth. In a letter to the editor, Parry et al. described a small, double-blind, randomized, placebocontrolled trial of $250 \mathrm{mg}$ of ciprofloxacin compared to placebo in a group of British mountaineers trekking in the Himalayas [29]. The primary end point was not a case definition of TD, but rather a decision by the expedition medical officer to break the code and to stop the trial medication. Among 21 participants (10 ciprofloxacin and 11 placebo) who completed the study, 6 of 11 placebo recipients met the end point criteria, whereas none of the 10 taking ciprofloxacin met the end point $(P<0.05)$. It was also noted that gastrointestinal complaints such as loose stools, cramping and nausea were decreased among those taking ciprofloxacin compared to placebo.

Taylor et al. reported the efficacy in a human experimental challenge study in which 15 volunteers were treated with $200 \mathrm{mg}$ tid rifaximin and 10 were randomized to placebo in a Shigella flexneri 2a (2457 T) challenge at 1,500 colony-forming units. In this study, there were no cases of shigellosis in the rifaximin group, compared with 6 of 10 in the placebo group becoming ill $(P=0.001)$ [32].

\section{Discussion}

This systematic review summarizes the findings of several studies showing a comparative advantage of antibiotic chemoprophylaxis for the prevention of TD. With respect to rifaximin chemoprophylaxis, two studies (Flores et al. and Armstrong et al.) did not show that chemoprophylaxis with rifaximin reached a statistically significant difference in preventing TD compared to placebo [25,27]. In both studies, the incidence of TD in the control group was relatively low (8 of 48 (17\%) and 9 of 47 (19\%), respectively), which could have explained the findings given that the sample size calculations were based on the expected incidence of TD of $40 \%$ and thus may have been too small to detect the true effect of rifaximin in preventing TD. Furthermore, though studies utilizing rifaximin were limited to only two regions, there appeared to be a consistent effect of protection at $67 \%$ (D\&L 95\% CI $=55 \%$ to $76 \%$ ) with little heterogeneity (heterogeneity $X^{2}=3.09, P=0.377 ; I^{2}=3.1 \%$ ), and the study by Taylor et al. suggests that rifaximin may be effective against more invasive pathogens occurring in other common travel destinations [32]. However, until such studies are done in field settings (and against a broader range of invasive pathogens to include nontyphoid Salmonella and Campylobacter), routine chemoprophylaxis against TD with rifaximin may not be appropriate if a traveler is going to destinations where diarrheagenic Escherichia coli are less common.

The effectiveness of fluoroquinolone antibiotics would appear to be greater than rifaximin, which is not surprising, given the broader spectrum of coverage and systemic distribution of this drug class. Pooled estimates of fluoroquinolone efficacy were $88 \%$ (95\% CI $80 \%$ to $93 \%$ ) with little evidence of heterogeneity (heterogeneity $X^{2}=1.25, P=0.87$; $I^{2}=0.0 \%$ ), though less effective when moderate to severe TD as an outcome is considered (summary D\&L efficacy of $49 \%$ ). It is important to note that studies examining fluoroquinolones were not as current as the studies that examined rifaximin (publication 1986 to 1994 vs. 2005 to 2011). As sanitation and hygiene conditions improve, resistance to fluoroquinolones emerges, and geographical patterns of resistance change (and keep evolving), older data citing fluoroquinolone use for chemoprophylaxis may become obsolete. The data from older studies of the use of fluoroquinolones may be less contemporaneous, but it is still valuable as it adds perspective and places newer data from rifaximin studies into context.

Although such a meta-analysis of the efficacy of antibiotics for TD prevention is interesting, the results do not necessarily compel one to embrace chemoprophylaxis as a potential solution. Even in the face of efficacy data for safer antibiotics such as rifaximin, the prevailing consensus is against widespread use exemplified by Dr. Gorbach, Chairman of the 1985 NIH Consensus Development Panel, who wrote an accompanying editorial to the first report of rifaximin diarrhea prophylactic efficacy in 2005 [13]. Gorbach's concerns included potential unintended adverse consequences, such as safety issues, uncertain protection against invasive pathogens, and microbiologic adverse effects, that may not yet be apparent in the small number of studied individuals. Dr. Gorbach concluded with the statement, "Rapid and judicious treatment of diarrhea, not antibiotic prophylaxis, is the best recommendation for most travelers."

Although these concerns still prevail today, a new consideration regarding the potential risk of postinfectious chronic health consequences of TD has arisen. Serious sequelae 
such as reactive arthritis [35] and Guillain-Barré syndrome [36] have long been known to be associated with infections causing TD, but they are relatively infrequent. Most notable has been the accumulating evidence associating TD with postinfectious irritable bowel syndrome. Two separate systematic reviews have now been published which conclude that roughly 1 of 11 people who develop acute diarrheal infection may go on to develop PI-IBS $[15,16]$. Other studies are also reporting TD risk with other common postinfectious functional gastrointestinal disorders [37-40]. With TD specifically, there have been six studies among traveler populations, all of which have shown an increased risk of PI-IBS among travelers who develop TD compared to those who do not develop TD [39-44]. Factors which appear to be associated with increased risk of PI-IBS include fever, illness severity, duration, infection with an invasive pathogen, and concomitant acute stress. Furthermore, this risk remains elevated for at least 3 years after the infection [16] and has been described to persist in $57 \%$ after 6 years in one study and $76 \%$ after 5 years in another $[45,46]$.

Thus, the recognition of both the acute and chronic consequences associated with TD diarrhea may change the riskbalance and value equation for antibiotic chemoprophylaxis. A recent economic analysis by Lundkvist $e t$ al., who evaluated the potential cost-effectiveness of a vaccine against enterotoxigenic $E$. coli, described the cost of a TD event of $\$ 1,460$ or $\$ 1,996$ for a leisure or business traveler, respectively (including value of travel, value of time, and medical costs) [47]. With regard to IBS, in a review of 18 economic studies conducted in the United States and United Kingdom, direct and indirect cost per patient-year were estimated between $\$ 700$ and $\$ 12,000$ (2002) [48]. In this systematic review, we found a NNT with chemoprophylaxis to prevent TD during travel of 2.8 (95\% CI $=2.0$ to 4.7 ) for fluoroquinolones and 4.5 (95\% $\mathrm{CI}=2.6$ to 15.9$)$ for rifaximin. A backof-the-envelope calculation would suggest that to prevent the cost of acute disease, a single-dose, 14-day regimen of rifaximin $550 \mathrm{mg}$ (at $\$ 22.61$ per dose, $\$ 316.58$ regimen) would provide a net benefit of $\$ 35$ for a leisure traveler $(\$ 1,460-(4.5 \times \$ 316.58))$ and a $\$ 571$ net benefit for the average business traveler to an average-risk region. Fluoroquinolones at less than $\$ 1.00$ per dose (ciprofloxacin) would appear to be even more cost-effective using a simplistic calculation. However, such cost savings need to be balanced by the cost of potential AEs associated with antibiotics. Interestingly, in this systematic review, there were no treatment emergent-related AEs reported for any of the studies, though the inclusion of risk of Clostridium difficile infection and fluoroquinolone-related tendonopathies ought to be considered more formally in an economic analysis. If one were to more comprehensively consider the value added in preventing PI-IBS and other chronic health consequences, the benefits of chemoprophylaxis in acute and chronic disease prevention may appear to outweigh the risks associated with chemoprophylaxis. Clearly, future studies are needed to better define the economic cost associated with PI-IBS and whether chemoprophylaxis with rifaximin or fluoroquinolones can be used safely to prevent such sequelae.

The present review includes a comprehensive literature search, a priori inclusion and exclusion criteria, standardized data abstraction, risk of bias scoring, and current analytic methods, all of which reduce the potential bias in the resultant population of studies used for analysis. However, the small number of studies and the lack of studies conducted among a variety of study population types and geographic regions limit the broad application of these results beyond young healthy travelers and, for rifaximin, to regions outside Central America, where diarrheagenic E. coli may not predominate. Though comprehensive, our search strategy might not have identified all eligible studies. We did not find heterogeneity in study effect estimates, but the studies evaluating fluoroquinolones were not current and thus may have been subject to changes in traveler population demographics and secular trends of antimicrobial resistance. Therefore, translation of results from this type of controlled setting to other populations who may be less healthy or subject to different travel or treatment environments need to be validated by additional studies. This systematic review afforded an objective assessment of study design and risk of bias for the population of chemoprophylaxis trials included. Although the risk of bias for most domains was considered low, the authors felt that there was incomplete data reporting for some studies, which could have included important secondary outcomes related to per-protocol or efficacy evaluable analyses and efficacy against moderate to severe disease. In addition, it was noted that not all studies included information on how they ensured or measured treatment adherence and what potential effect such nonadherence may have had on study results. Given the known problem of medication adherence with malaria chemoprophylaxis, such an assessment for TD adherence within these trial settings would be informative [49,50]. Last, some studies had significant lost to follow-up rates, which, though generally balanced across treatment arms, raises further concern about self-selection bias and the generalizability of these results. Future studies ought to consider better methods to ensure avoidance of dropouts and losses to follow-up, which can be a challenge in a travel setting.

\section{Conclusions}

It is crucial that clinicians, including pharmacists who practice in a travel clinic setting, stay well-informed on geographical patterns, itineraries, traveler behaviors and areas where the risk of developing TD is high (high-risk areas). If a traveler is planning on taking a short-term trip $(\leq 14$ days in duration) to an area where the risk for developing TD is high and diarrheagenic E. coli pathogens predominate, the data reviewed in this study support the authors' opinion that routine chemoprophylaxis with rifaximin may be a 
reasonable choice if the patient does not have any contraindications for use.

\section{Competing interests}

MR has served on scientific advisory boards for and received research grants from Salix Pharmaceuticals (Morrisville, NC, USA). All other authors declare that they have no competing interests. This study was conducted by each author without internal or external funding.

\section{Authors' contributions}

SA and MR participated in design of the study, conducted literature search, and contributed to manuscript development. SA conducted statistical analysis and abstraction of data. JS participated in quality review, validation of abstracted data, and significant manuscript edits. DA participated in design and coordination of study and helped draft the manuscript. All authors read and approved the final manuscript.

\section{Copyright statement}

Two of the authors (JS and M.R.) are employees of the U.S. Government and military service members. This work was prepared as part of official duties. Title 17 USC $\S 105$ provides that "Copyright protection under this title is not available for any work of the United States Government." Title 17 USC $\S 101$ defines a U.S. Government work as a work prepared by a military service member or employee of the U.S. Government as part of that person's official duties.

\section{Disclaimer}

The views expressed in this article are those of the author and do not necessarily reflect the official policy or position of the Department of the Navy, Department of Defense or the U.S. Government. This is a U.S. Government work. There are no restrictions on its use.

\section{Human subjects protection}

This is not human subjects research and therefore is exempt from Institutional Review Board review.

\section{Author details}

${ }^{1}$ School of Pharmacy, University of Washington, Seattle, WA, USA. ${ }^{2}$ Naval Medical Research Center, Silver Spring 20910-7500 MD, USA. ${ }^{3}$ PATH, Seattle, WA, USA.

Received: 31 May 2012 Accepted: 13 August 2012

Published: 28 August 2012

\section{References}

1. Shah N, DuPont HL, Ramsey DJ: Global etiology of travelers' diarrhea: systematic review from 1973 to the present. Am J Trop Med Hyg 2009, 80:609-614.

2. Riddle MS, Halvorson HA, Shiau D, Althoff J, Monteville MR, Shaheen H, Horvath $E P$, Armstrong AW: Acute gastrointestinal infection, respiratory illness, and noncombat injury among US military personnel during Operation Bright Star 2005, in Northern Egypt. J Travel Med 2007, 14:392-401.

3. Shlim DR: Looking for evidence that personal hygiene precautions prevent traveler's diarrhea. Clin Infect Dis 2005, 41(Suppl 8):S531-S535.

4. Heywood AE, Zhang M, Maclntyre CR, Seale H: Travel risk behaviours and uptake of pre-travel health preventions by university students in Australia. BMC Infect Dis 2012, 12:43.

5. Yanni EA, Marano N, Han P, Edelson PJ, Blumensaadt S, Becker M, Dwyer S, Crocker K, Daley T, Davis X, Gallagher N, Balaban V, McCarron M, Mounts A, Lipman H, Brown C, Kozarsky P: Knowledge, attitudes, and practices of US travelers to Asia regarding seasonal influenza and $\mathrm{H} 5 \mathrm{~N} 1$ avian influenza prevention measures. J Travel Med 2010, 17:374-381.

6. Namikawa K, lida T, Ouchi K, Kimura M: Knowledge, attitudes, and practices of Japanese travelers on infectious disease risks and immunization uptake. J Travel Med 2010, 17:171-175.

7. Hartjes LB, Baumann LC, Henriques JB: Travel health risk perceptions and prevention behaviors of US study abroad students. J Travel Med 2009, 16:338-343.

8. Steffen R, Connor BA: Vaccines in travel health: from risk assessment to priorities. J Travel Med 2005, 12:26-35.
9. Office of Medical Applications of Research, National Institutes of Health; $\mathrm{NIH}$ Consensus Development Conference: Travelers' diarrhea. JAMA 1985, 253:2700-2704.

10. Reves RR, Johnson PC, Ericsson CD, DuPont HL: A cost-effectiveness comparison of the use of antimicrobial agents for treatment or prophylaxis of travelers' diarrhea. Arch Intern Med 1988, 148:2421-2427.

11. Thomson MA, Booth IW: Treatment of traveller's diarrhoea: economic aspects. Pharmacoeconomics 1996, 9:382-391.

12. DuPont HL: New insights and directions in travelers' diarrhea. Gastroenterol Clin North Am 2006, 35:337-353. viii-ix.

13. Gorbach SL: How to hit the runs for fifty million travelers at risk. Ann Intern Med 2005, 142:861-862.

14. Hill DR, Ericsson CD, Pearson RD, Keystone JS, Freedman DO, Kozarsky PE, DuPont HL, Bia FJ, Fischer PR, Ryan ET, Infectious Diseases Society of America: The practice of travel medicine: guidelines by the Infectious Diseases Society of America. Clin Infect Dis 2006, 43:1499-1539.

15. Halvorson HA, Schlett CD, Riddle MS: Postinfectious irritable bowel syndrome: a meta-analysis. Am J Gastroenterol 2006, 101:1894-1899.

16. Thabane M, Kottachchi DT, Marshall JK: Systematic review and meta-analysis: the incidence and prognosis of post-infectious irritable bowel syndrome. Aliment Pharmacol Ther 2007, 26:535-544.

17. Koo HL, DuPont HL: Rifaximin: a unique gastrointestinal-selective antibiotic for enteric diseases. Curr Opin Gastroenterol 2009, 26:17-25.

18. Koo HL, DuPont HL: Current and future developments in travelers' diarrhea therapy. Expert Rev Anti Infect Ther 2006, 4:417-427.

19. Ericsson CD: Travellers' diarrhoea. Int J Antimicrob Agents 2003, 21:116-124.

20. DuPont HL: Systematic review: prevention of travellers' diarrhoea. Aliment Pharmacol Ther 2008, 27:741-751.

21. DuPont HL: Travellers' diarrhoea: contemporary approaches to therapy and prevention. Drugs 2006, 66:303-314.

22. Chapman AS, Witkop CT, Escobar JD, Schlorman CA, DeMarcus LS, Marmer LM, Crum ME: Norovirus outbreak associated with person-to-person transmission, U.S. Air Force Academy, July 2011. MSMR 2011, 18:2-5.

23. Harbord RM, Egger M, Sterne JA: A modified test for small-study effects in meta-analyses of controlled trials with binary endpoints. Stat Med 2006, 25:3443-3457.

24. Johnson PC, Ericsson CD, Morgan DR, Dupont HL, Cabada FJ: Lack of emergence of resistant fecal flora during successful prophylaxis of traveler's diarrhea with norfloxacin. Antimicrob Agents Chemother 1986, 30:671-674.

25. Cohen D, Shoham O, Orr N, Muhsen K: An inverse and independent association between Helicobacter pylori infection and the incidence of shigellosis and other diarrheal diseases. Clin Infect Dis 2012, 54:e35-e42.

26. DuPont HL, Jiang ZD, Okhuysen PC, Ericsson CD, de la Cabada FJ, Ke S, DuPont MW, Martinez-Sandoval F: A randomized, double-blind, placebo-controlled trial of rifaximin to prevent travelers' diarrhea. Ann Intern Med 2005, 142:805-812.

27. Flores J, DuPont $\mathrm{HL}$, Jiang ZD, Okhuysen PC, Melendez-Romero JH, Gonzalez-Estrada A, Carrillo I, Paredes M: A randomized, double-blind, pilot study of rifaximin $550 \mathrm{mg}$ versus placebo in the prevention of travelers' diarrhea in Mexico during the dry season. J Travel Med 2011, 18:333-336.

28. Martinez-Sandoval F, Ericsson CD, Jiang ZD, Okhuysen PC, Romero $\mathrm{JH}$, Hernandez N, Forbes WP, Shaw A, Bortey E, DuPont HL: Prevention of travelers' diarrhea with rifaximin in US travelers to Mexico. J Travel Med 2010, 17:111-117.

29. Parry H, Howard AJ, Galpin OP, Hassan SP: The prophylaxis of travellers' diarrhoea: a double blind placebo controlled trial of ciprofloxacin during a Himalayan expedition. J Infect 1994, 28:337-338.

30. Rademaker CM, Hoepelman IM, Wolfhagen MJ, Beumer H, Rozenberg-Arska M, Verhoef J: Results of a double-blind placebo-controlled study using ciprofloxacin for prevention of travelers' diarrhea. Eur I Clin Microbiol Infect Dis 1989, 8:690-694.

31. Wiström J, Norrby SR, Burman LG, Lundholm R, Jellheden B, Englund G: Norfloxacin versus placebo for prophylaxis against travellers' diarrhoea. J Antimicrob Chemother 1987, 20:563-574.

32. Taylor DN, McKenzie R, Durbin A, Carpenter C, Atzinger CB, Haake R, Bourgeois AL: Rifaximin, a nonabsorbed oral antibiotic, prevents shigellosis after experimental challenge. Clin Infect Dis 2006, 42:1283-1288.

33. Heck JE, Staneck JL, Cohen MB, Weckbach LS, Giannella RA, Hawkins J, Tosiello R: Prevention of travelers' diarrhea: ciprofloxacin versus trimethoprim/sulfamethoxazole in adult volunteers working in Latin America and the Caribbean. J Travel Med 1994, 1:136-142. 
34. Scott DA, Haberberger RL, Thornton SA, Hyams KC: Norfloxacin for the prophylaxis of travelers' diarrhea in U.S. military personnel. Am J Trop Med Hyg 1990, 42:160-164.

35. Yates JA, Stetz LC: Reiter's syndrome (reactive arthritis) and travelers' diarrhea. J Travel Med 2006, 13:54-56.

36. Butzler JP: Campylobacter, from obscurity to celebrity. Clin Microbiol Infect 2004, 10:868-876.

37. Tuteja AK, Talley NJ, Gelman SS, Alder SC, Thompson C, Tolman K, Hale DC Development of functional diarrhea, constipation, irritable bowel syndrome, and dyspepsia during and after traveling outside the USA. Dig Dis Sci 2008, 53:271-276.

38. Parry SD, Stansfield R, Jelley D, Gregory W, Phillips E, Barton JR, Welfare MR: Does bacterial gastroenteritis predispose people to functional gastrointestinal disorders? A prospective, community-based, case-control study: Frequency of FGID After Gastroenteritis. Am J Gastroenterol 2003, 98:1970-1975.

39. Porter CK, Gloor K, Cash BD, Riddle MS: Risk of functional gastrointestinal disorders in U.S. military following self-reported diarrhea and vomiting during deployment. Dig Dis Sci 2011, 56:3262-3269.

40. Trivedi KH, Schlett CD, Tribble DR, Monteville MR, Sanders JW, Riddle MS: The impact of post-infectious functional gastrointestinal disorders and symptoms on the health-related quality of life of US military personnel returning from deployment to the Middle East. Dig Dis Sci 2011, 56:3602-3609.

41. Pitzurra R, Fried M, Rogler G, Rammert C, Tschopp A, Hatz C, Steffen R, Mutsch M: Irritable bowel syndrome among a cohort of European travelers to resource-limited destinations. J Travel Med 2011, 18:250-256.

42. Innckyj A, Balachandra B, Elliott L, Choudhri S, Duerksen DR: Post-traveler's diarrhea irritable bowel syndrome: a prospective study. Am J Gastroenterol 2003, 98:596-599.

43. Okhuysen PC, Jiang ZD, Carlin L, Forbes C, DuPont HL: Post-diarrhea chronic intestinal symptoms and irritable bowel syndrome in North American travelers to Mexico. Am J Gastroenterol 2004, 99:1774-1778.

44. Stermer E, Lubezky A, Potasman I, Paster E, Lavy A: Is traveler's diarrhea a significant risk factor for the development of irritable bowel syndrome? A prospective study. Clin Infect Dis 2006, 43:898-901.

45. Neal KR, Barker L, Spiller RC: Prognosis in post-infective irritable bowel syndrome: a six year follow up study. Gut 2002, 51:410-413.

46. Törnblom H, Holmvall P, Svenungsson B, Lindberg G: Gastrointestinal symptoms after infectious diarrhea: a five-year follow-up in a Swedish cohort of adults. Clin Gastroenterol Hepatol 2007, 5:461-464.

47. Lundkvist J, Steffen R, Jönsson B: Cost-benefit of WC/rBS oral cholera vaccine for vaccination against ETEC-caused travelers' diarrhea. J Travel Med 2009, 16:28-34.

48. Maxion-Bergemann S, Thielecke F, Abel F, Bergemann R: Costs of irritable bowel syndrome in the UK and US. Pharmacoeconomics 2006, 24:21-37.

49. Lobel HO, Phillips-Howard PA, Brandling-Bennett AD, Steffen R, Campbell CC, Huong AY, Were JB, Moser R: Malaria incidence and prevention among European and North American travellers to Kenya. Bull World Health Organ 1990, 68:209-215.

50. Steffen R, Heusser R, Mächler R, Bruppacher R, Naef U, Chen D, Hofmann AM, Somaini B: Malaria chemoprophylaxis among European tourists in tropical Africa: use, adverse reactions, and efficacy. Bull World Health Organ 1990, 68:313-322.

doi:10.1186/2046-4053-1-39

Cite this article as: Alajbegovic et al: Effectiveness of rifaximin and fluoroquinolones in preventing travelers' diarrhea (TD): a systematic review and meta-analysis. Systematic Reviews 2012 1:39.

\section{Submit your next manuscript to BioMed Central and take full advantage of:}

- Convenient online submission

- Thorough peer review

- No space constraints or color figure charges

- Immediate publication on acceptance

- Inclusion in PubMed, CAS, Scopus and Google Scholar

- Research which is freely available for redistribution

Submit your manuscript at www.biomedcentral.com/submit
C Biomed Central 